NASZA DERMATOLOGIA Online OUR DERMATOLOGY Online Nil

Competing Interests: None

\section{RECURRENT POSTCOITAL FIXED DRUG ERUPTION CAUSED BY CO-TRIMOXAZOLE MIMICKING A SEXUALLY INDUCED DISEASE}

\author{
Marko Vok
}

Dermato-Venereal Clinic, Ulica oktobrske revolucije 11 6310, Izola, Slovenia

Corresponding author: Dr Marko Vok

marko.vok@siol.net

\begin{abstract}
We report a case of a woman which had in 6-months three episodes of a recurrent postcoital skin eruption, each lasting for a few weeks. It seemed like a sexually induced eruption. She admitted to take only her permanent therapy that could not be connected to her skin signs. Thanks to her Health Insurance Card with the digital record of all the drugs she had received in the last two years it was possible to find out that she was intermittently taking co-trimoxazole in order to prevent an after intercourse urinary bladder infection. A good evidence of the patient's medication has a key role in the diagnosis of skin adverse drug reactions. Fixed drug eruption is a common adverse drug reaction and everyone prescribing a long term antibiotic prophylaxis should be aware of it.
\end{abstract}

Key words: postcoital fixed drug eruption; co-trimoxazole; therapy digital recording

\section{Introduction}

Fixed drug eruption (FDE) is a common adverse drug reaction. Co-trimoxazole, a combination of sulphamethoxazole and trimethoprim, is one of the most frequent causative agents. Co-trimoxazole induced FDE is often located on the male genital $[1,2]$. It can be also caused during the sexual intercourse by genital fluids of the partner taking the drug systemically or locally [3,4]. We report a case of a recurrent FDE appearing after the intercourse, although not induced by it.

\section{Case Report}

A 41-year-old woman reported three episodes of skin and oral mucous eruption from October 2011 till March 2012 each time following a sexual intercourse with her husband. Multiple acute lesions developed the day after the intercourse as sharply marginate, round or oval, burning erythema multiforme-like plaques with a 1 to $5 \mathrm{~cm}$ diameter, lasting for about a week and followed by some weeks lasting pigmentations. Multiple lesions were on the trunks, limbs and sometimes on the oral mucous (Fig. 1-4).

She regularly takes levothyroxin and a combination of drospirenon and ethynilestradiol tablets. She denied taking other medicaments. Thanks to the Health Insurance Card System we could see on her card the digital record of all the drugs she acquired in the last two years (Fig. 5). So, we saw that her general practitioner had prescribed her two boxes of co-trimoxazole in April 2011. After we had warned her, she remembered that she used to take a half or whole tablet of co-trimoxazole after the intercourse in order to prevent a urinary bladder infection to which she was prone. Partly she attributed it to her husband insulin dependent diabetes mellitus. He regularly takes insulin and metformin. In the past our patient had already taken co-trimoxazole tablets several times, but she has started to experience problems only since October 2011. She was not quite sure if she took a tablet after every intercourse, but mostly she did.

In our opinion the diagnosis of FDE to co-trimoxazole was clear-cut. We recommended her to avoid it. In the ten months period after she had stopped taking co-trimoxazole the FDE did not recur.

\section{Discussion}

The diagnosis of FDE is considered as easy when the presentation and the course of the disease are typical. FDE usually appears as a solitary or multiple, well circumscribed, erythematous-violaceous oedematous plaques and in a regression period into some weeks lasting pigmentations. The lesions usually recur 30 minutes to 8 hours after the exposure to the causative drug at the same sites of the previous eruption. 


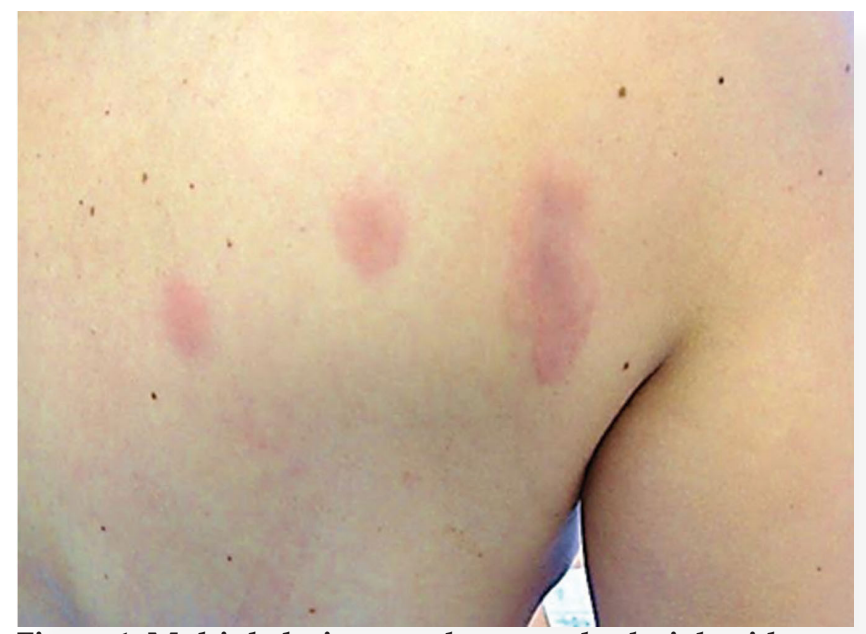

Figure 1. Multiple lesions on the upper back right side

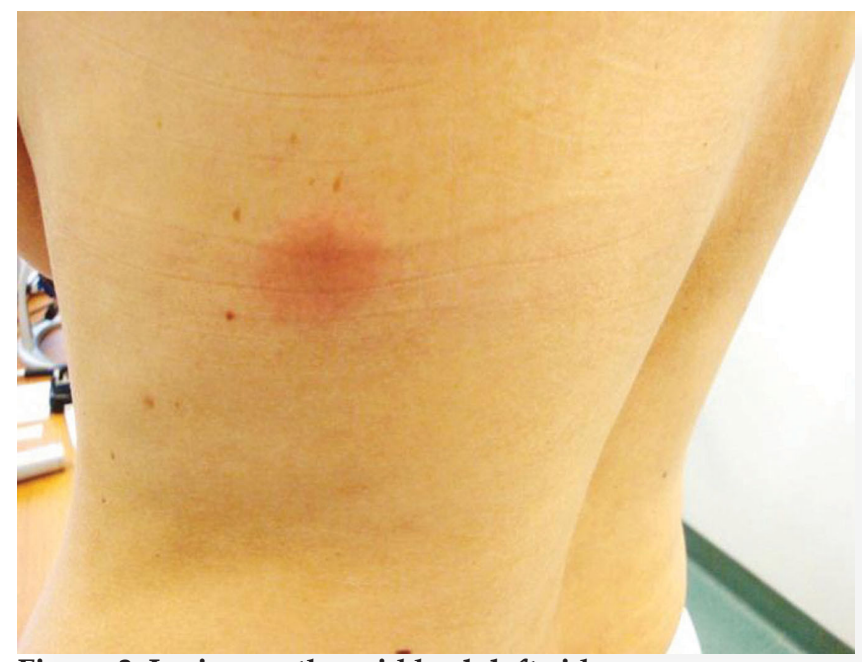

Figure 3. Lesion on the mid back left side

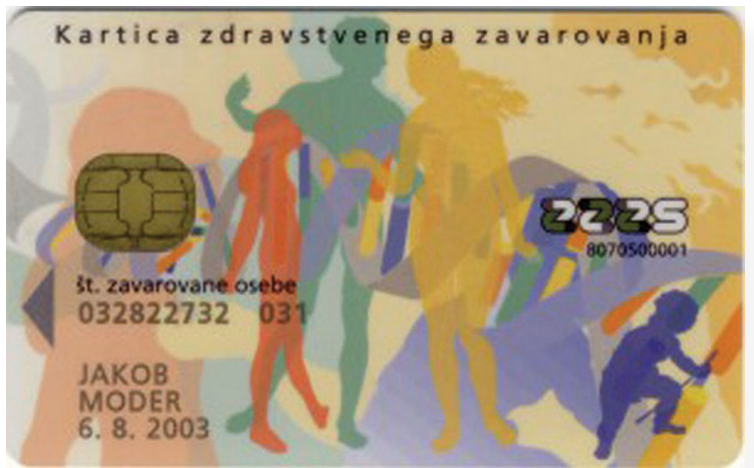

Figure 5. Sample of the Slovenian Digital Health Insurance Card

The previously involved sites do not flare with each exposure, which is known as the refractory period. The duration of this period varies from a few weeks to several months. It seems that FDE develops more frequently to intermittently receiving drugs than to those taking permanently. The sensitization period varies from some weeks to several years [5]. There are some reports of spontaneous or induced desensitization to the causative drug in cases of FDE. The exact mechanism

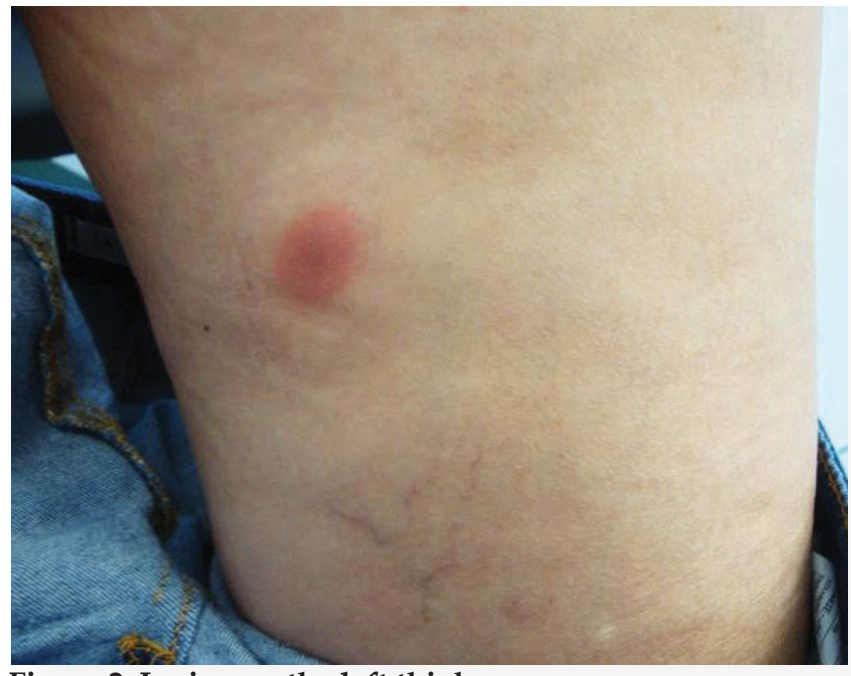

Figure 2. Lesion on the left thigh

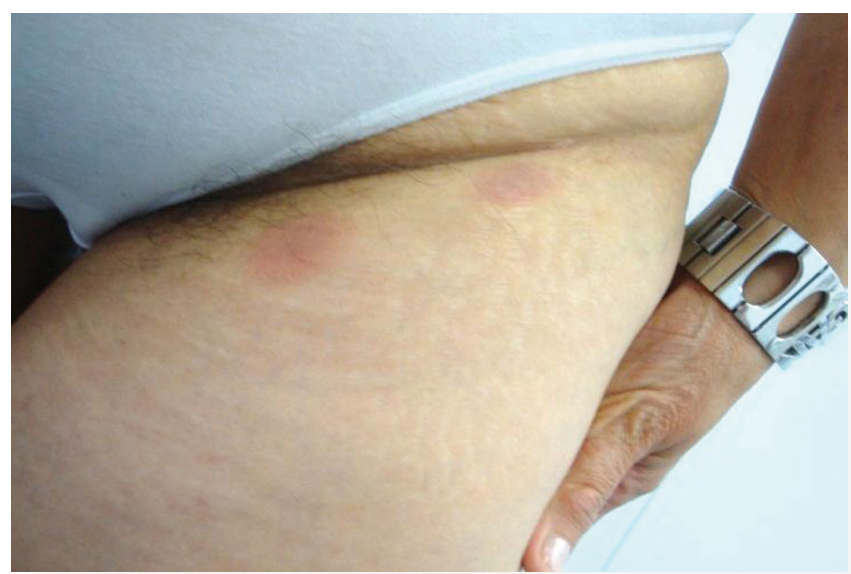

Figure 4. Two lesions on the left groin

of tolerance induction is still poorly understood [6,7].

Our reported case of FDE to co-trimoxazole is a quite typical case for its clinical picture, course, latency period from intake to appearance, refractory period, several years lasting sensitization period and for being caused by an intermittently taken drug.

In the pathogenesis of FDE epidermal $\mathrm{CD} 8^{+} \mathrm{T}$ cells resident in the FDE lesions have a major role. FDE is considered a $\mathrm{T}$ cell mediated delayed drug hypersensitivity reaction with important specificities in the effector cells involved [8].

Oral challenge is considered the most reliable method for establishing the causative drug in FDE. It is usually performed by administering a single dose of the suspected drug, starting at one-tenth of the therapeutic dose [5]. In some rare cases it should be kept in mind that the oral challenge may induce a severe reaction.

Patch testing represents a simple and safe screening test especially when multiple drugs are suspected. A positive patch test reaction is usually a strong evidence of a causative drug. A negative patch test does not exclude a possible hypersensitivity. 
The patch test should be always done in the site of a previous lesion at least two weeks after its disappearance (refractory period). Persistent lack of reactivity to some drugs is an important limitation. One of the reasons of the false negative patch test result could be the impaired penetration of the specific drug through the stratum corneum, the other that the patient may not be sensitized to the original drug but to its metabolites [5,9].

Patch testing with co-trimoxazole in FDE is not yet standardized. The available commercial hapten of cotrimoxazole is a $10 \%$ dilution in petrolatum. But it seems that petrolatum is not a suitable vehicle and that dimethylsulfoxide is more appropriate. Özkaya-Bayazit et al. reported of 25 positive reactions (20 to sulphamethoxazole and 5 to trimethoprim) in 27 patients with co-trimoxazole FDE patch tested with different concentrations of sulphametoxazole and trimethoprim diluted in dimethylsulfoxide, while all patients had negative results when they used petrolatum as a vehicle [10].

In our patient we did not perform any diagnostic test because there was no need for that. In fact, the patient had done the challenge test herself the evening before the visit by having sex with her husband and the usual taking of a tablet of cotrimoxazole after the intercourse. Only that she attributed the skin symptoms to the intercourse and not to the drug.

\section{Conclusions}

Our case shows the importance of the information of drugs taken by patients. For different reasons they often omit to mention all the drugs that they take. In these cases an accompanying electronic evidence of the prescribed drugs could be crucial to solve the problem of an adverse drug reaction. Our case also shows how misleading can be the history of the disease. In our patient it was typical for a sexually induced skin eruption. In fact it was the consequence of a relatively common after intercourse antibiotic prophylaxis of urinary bladder infections. The possibility of a cutaneous adverse drug reaction should be considered by everyone prescribing a long term intermittent antibiotic prophylaxis.

\section{REFERENCES}

1. Özkaya-Bayazit E, Bayazit H, Özarmağan G: Drug related clinical pattern in fixed drug eruption. Eur J Dermatol. 2000;10:288-91.

2. Abreu Velez AM, Klein AD, Howard MS: An allergic bullous drug reaction triggered by levofloxacin and trimethoprim/ sulfamethoxazole mimicking an autoimmune blistering disease. Our Dermatol Online. 2012;3:341-3.

3. Gruber F, Stasić A, Lenković M, Brajac I: Postcoital fixed drug eruption in a man sensitive to trimethoprim-sulphamethoxazole. Clin Exp Dermatol. 1997;22:144-5.

4. Zargooshi J, Kavoussi H, Rahmanian E, Motaee H, Kohzadi M, Nourizad S: Postcoital penile drug eruption in a co-trimoxazolesensitive patient following vaginal use of triple sulfa vaginal cream by his partner. J Sex Med. 2012;9:758-60.

5. Shiohara T: Fixed drug eruption: pathogenesis and diagnostic tests. Curr Opin Allergy Clin Immunol. 2009;9:316-21.

6. Kelso JM, Keating RM: Successful desensitization for treatment of a fixed drug eruption to allopurinol. J Allergy Clin Immunol. 1996;97:1171-2.

7. Patriarca G, Schiavino D, Buonomo A, Aruanno A, Altomonte G, Nucera E: Desensitization to co-trimoxazole in a patient with fixed drug eruption. J Investig Allergol Clin Immunol. 2008;18:309-11.

8. Gómez E, Torres MJ, Mayorga C, Blanca M: Immunologic evaluation of drug allergy. Allergy Asthma Immunol Res. 2012;4:251-63

9. Andrade P, Brinca A, Gonçalo M: Patch testing in fixed drug eruptions - a 20-year review. Contact Dermatitis. 2011;65:195-201. 10. Özkaya-Bayazit E, Bayazit H, Özarmağan G: Topical provocation in 27 cases of cotrimoxazole-induced fixed drug eruption. Contact Dermatitis. 1999;41:185-9.

Copyright by Marko Vok. This is an open access article distributed under the terms of the Creative Commons Attribution License, which permits unrestricted use, distribution, and reproduction in any medium, provided the original author and source are credited. 